\title{
TREATMENT OF DISPLACED PROXIMAL HUMERAL FRACTURES IN ELDERLY PATIENTS
}

\author{
KAROL ZYTO, LEIF AHRENGART, ANDERS SPERBER， HANS TÖRNKVIST \\ From Söder Hospital and the Karolinska Institute, Stockholm, Sweden
}

We randomised 40 elderly patients of mean age 74 years with displaced three- or four-part fractures of the humerus to either conservative treatment or tension-band osteosynthesis.

At one year and after three to five years, clinical follow-up showed no functional differences between the two groups of patients, with optimal function achieved within one year. There were major complications only in the surgically-treated group. Radiological review showed that surgery had improved the position of the fractured humeral head, but this was not reflected in improved function.

Semi-rigid fixation with tension-band wiring of displaced multifragment fractures of the proximal humerus in the elderly did not improve the functional outcome when compared with conservative treatment.

J Bone Joint Surg [Br] 1997;79-B:412-7.

Received 18 November 1996; Accepted 6 January 1997

Proximal humeral fractures represent $4 \%$ to $5 \%$ of all fractures seen in accident and emergency departments. ${ }^{1}$ Non-displaced two-part fractures, according to Neer's classification, are the most common and it is generally agreed that they have a good prognosis after conservative treatment. ${ }^{2-4}$ The management of comminuted displaced fractures, however, remains controversial. ${ }^{3,5}$ These three- and four-part fractures ${ }^{2}$ represent $13 \%$ to $16 \%$ of all proximal humeral fractures. ${ }^{1}$

Twenty years ago the enthusiasm for early mobilisation

K. Zyto, MD, Consultant

H. Törnkvist, $\mathrm{PhD}$, Associate Professor

Department of Orthopaedics, Söder Hospital, S-118 83 Stockholm, Sweden.

L. Ahrengart, $\mathrm{PhD}$, Associate Professor

A. Sperber, MD, Consultant

Huddinge University Hospital, S-14186 Huddinge, Sweden.

Correspondence should be sent to Dr K. Zyto.

(C)1997 British Editorial Society of Bone and Joint Surgery 0301-620X/97/37419\$2.00 and the availability of better fixation devices popularised treatment by open reduction and internal fixation. The blood supply of the humeral head, however, puts its viability at risk not only from the injury but also from the softtissue exposure to reduce the fracture and insert implants. ${ }^{6}$ Malunion, nonunion, and particularly avascular necrosis (AVN) have been reported in patients treated by open reduction and internal fixation. ${ }^{2,7,8}$ The operative treatment of displaced fractures of the proximal humerus is therefore a technical challenge. In elderly patients, osteopenic bone, often in combination with a thin and or ruptured rotator cuff, predisposes to unpredictable clinical results.

Some studies show an acceptable outcome after the conservative treatment of complex fractures, ${ }^{9-11}$ and replacement of the humeral head has been reported as giving excellent results. ${ }^{2,12-17}$ Various methods of osteosynthesis have been suggested; the results reported vary from excellent to poor. Semi-tubular straight or angulated blade plates, ${ }^{6,8,18-20}$ screws, ${ }^{8}$ Rush nails, ${ }^{21}$ external fixators, ${ }^{22}$ and cerclage wiring alone ${ }^{6,21}$ or in combination with a tensionband technique ${ }^{23,24}$ have all been used.

Because extensive exposure and the insertion of large metal implants increase the risk of $\mathrm{AVN}^{6,25}$ the use of a limited exposure and minimal internal fixation ${ }^{8}$ has been recommended. Our study compared a tension-band technique with the conservative management of displaced three- and four-part fractures of the proximal humerus in elderly patients using functional and radiological assessment.

\section{PATIENTS AND METHODS}

All patients with proximal humeral fractures seen at the Huddinge University Hospital in Stockholm from April 1990 to February 1993 were considered for inclusion in the study if they fulfilled the following criteria: a displaced three- or four-part fracture of the humerus not caused by high-energy trauma and not pathological; at least $30 \%$ contact between the humeral head and the humeral shaft; no other fractures elsewhere in the upper limbs; no concomitant disease likely to influence the end result; and ability of the patient to co-operate. The study was approved by the local ethics committee. There were 40 patients, 35 women and five men, of mean age 74 years. They were 
Table I. Details of the 40 patients studied

\begin{tabular}{lll}
\hline & Operation & Conservative \\
\hline Mean age in years (SD) & $73 \pm 7.5$ & $75 \pm 6.7$ \\
Female:male & $18: 2$ & $17: 3$ \\
Fracture & & \\
$\quad$ Three-part & 19 & 18 \\
$\quad$ Four-part & 1 & 2 \\
Right:left side & $6: 14$ & $8: 12$ \\
Dominant limb & 7 & 9 \\
\hline
\end{tabular}

randomised by sealed envelope into either a surgical or conservative treatment group. Table I gives the details of the groups.

Treatment. In the conservative group the injured arm was supported in a sling for seven to ten days, followed by physiotherapy according to a standard regimen. No attempt was made to manipulate the fracture.

In the surgical group tension-band surgery was performed within 48 hours of admission by one of three senior orthopaedic surgeons (LA, AS, HT). Under general anaesthesia and through a deltopectoral incision, the cephalic vein and the deltopectoral groove were identified. The deltoid was retracted laterally but was not released from the clavicle. The long biceps tendon was dissected to the top of the humeral head and served as a guide for the correct positioning of the tuberosities and the rotation of the arm. The fracture fragments were identified without further dissection from the rotator cuff. One or two cerclage wires were passed underneath the rotator cuff to reduce and stabilise the tuberosities to the humeral head and the shaft (Figs 1a and 1b). In a few cases Kirschner wires were used to form a tension-band fixation. The patients received prophylactic cephalosporin perioperatively. The same physiotherapy regime was used for the patients in the conservative group.

The patients were reviewed clinically and radiologically immediately after treatment, at one year and after a minimum of three years to detect complications during the first year and to assess the functional outcome.

Of the 40 patients two were lost before one year and a further nine by the time of final follow-up. Eight of these patients had died from unrelated causes, two could not be contacted and one in the conservative group had replacement of the humeral head after another fall with more displacement of the fracture. Thirty-eight patients remained at the one-year follow-up and 29 at the final follow-up. There were four men and 25 women; 14 had been treated

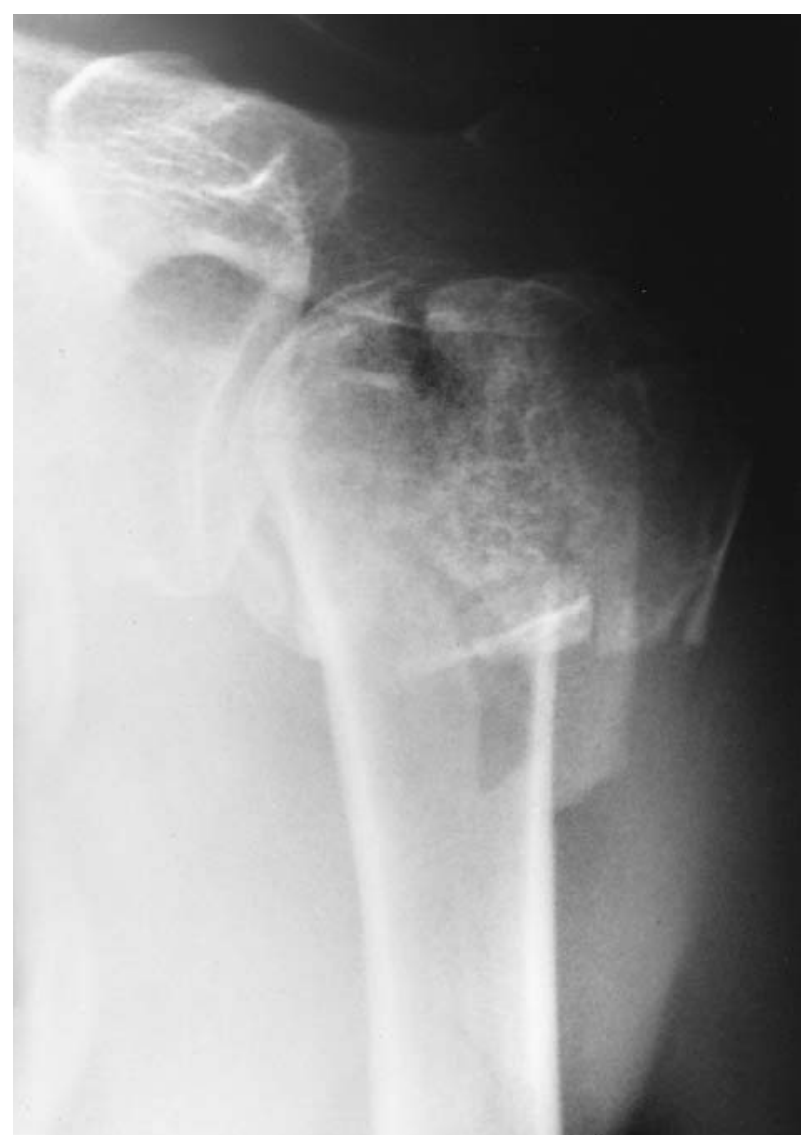

Fig. 1a

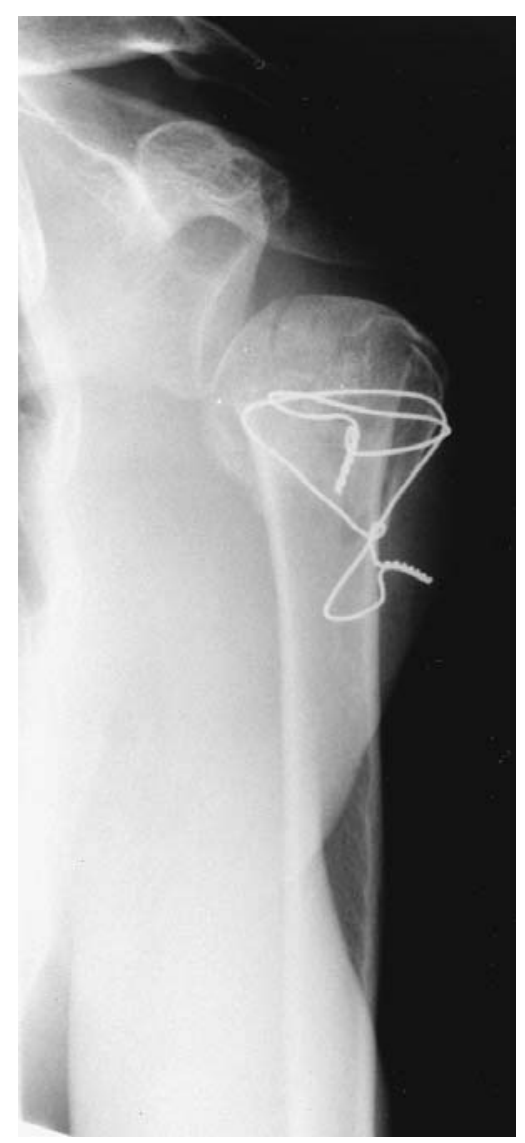

Fig. 1b

Radiographs of a four-part fracture preoperatively (a) and after reduction and cerclage wire fixation (b). 
Table II. Subjective assessment of function by the patients at 12 months and at the final follow-up. 'Yes' or 'no' answers were elicited to the questions listed in the left column. 'Yes' answers are given by number and percentage

\begin{tabular}{|c|c|c|c|c|}
\hline & \multicolumn{2}{|l|}{12 months } & \multicolumn{2}{|l|}{50 months } \\
\hline & Operation $(n=19)$ & Conservative $(n=19)$ & Operation $(n=14)$ & Conservative $(n=15)$ \\
\hline $\begin{array}{l}\text { Sleep on the } \\
\text { fractured side }\end{array}$ & $13(68)$ & $15(79)$ & $11(78)$ & $13(86)$ \\
\hline $\begin{array}{l}\text { Reach to the top } \\
\text { of the head }\end{array}$ & $16(84)$ & $19(100)$ & $11(78)$ & $15(100)$ \\
\hline Comb hair & $16(84)$ & $16(84)$ & $12(85)$ & $12(80)$ \\
\hline Reach to the mouth & $19(100)$ & $19(100)$ & $14(100)$ & $15(100)$ \\
\hline $\begin{array}{l}\text { Reach to the } \\
\text { opposite axilla }\end{array}$ & $17(89)$ & $16(84)$ & $13(92)$ & $15(100)$ \\
\hline Reach to the groin & $19(100)$ & $19(100)$ & $14(100)$ & $15(100)$ \\
\hline Reach to the buttock & $16(84)$ & $19(100)$ & $13(92)$ & $13(86)$ \\
\hline Reach to $\mathrm{T} 7$ & $6(32)$ & $8(42)$ & $5(35)$ & $10(66)$ \\
\hline $\begin{array}{l}\text { Manage personal } \\
\text { hygiene }\end{array}$ & $13(68)$ & $14(73)$ & $13(92)$ & $11(73)$ \\
\hline Carry $5 \mathrm{~kg}$ & $9(47)$ & $11(57)$ & $9(64)$ & $8(53)$ \\
\hline
\end{tabular}

surgically and 15 conservatively.

Functional assessment was at the one-year follow-up and was repeated with the use of the Constant and Murley ${ }^{26}$ scoring system at final follow-up. At the final review the patients were examined by one of the authors (KZ) who had not been involved in their primary management.

The patients were sent a questionnaire one year after the fracture, and at the time of the final follow-up. Table II gives the details. The clinical examination was expressed as the Constant and Murley ${ }^{26}$ score using the clinical criteria of pain (15 points), range of motion (40 points), power (25 points) and activities of daily living (20 points). Pain had a four-level scale - none (15 points), mild (10 points), moderate ( 5 points) or severe ( 0 points $)$ - and a visual analogue scale (VAS) from zero (no pain) to ten (maximum pain). By subtracting the points on the VAS scale from the four-level scale, the final subjective score of pain was achieved. Range of motion was measured using a goniometer. The patient's active painless flexion, abduction, external and internal rotation were measured. For the power measurements of the shoulder muscles a spring balance was used. The elbow was held straight, while the patient maintained resisted elevation against the pull of the spring balance for a period of 5 seconds. The tests were performed with the shoulder at $90^{\circ}$ of flexion or at whatever level below $90^{\circ}$ was found to be painless by the patient. The mean of three tests was recorded as the power strength of the shoulder. Activities of daily living which were assessed included ability to work, leisure or sports activities and undisturbed sleep.

Anteroposterior and lateral radiographs were taken and used to assess fracture position, osteoarthritis, AVN and nonunion. They were independently examined by a radiologist and by one of the authors (KZ). Dislocation of the tuberosities, the operative reduction of the fracture and the dorsal angulation of the humeral head were assessed (Fig. 2)

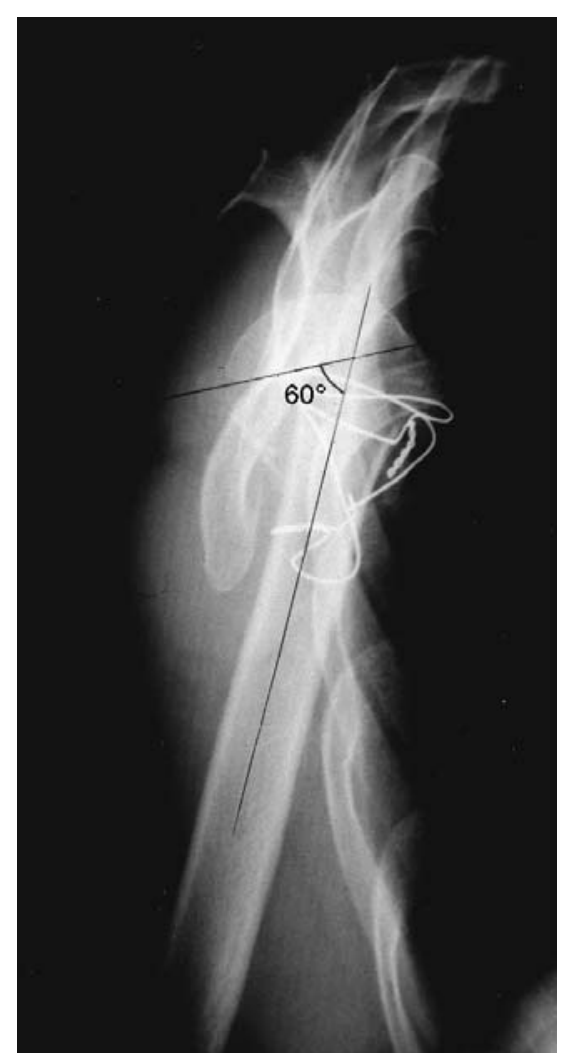

Fig. 2

Method of assessment of dorsal angulation of the humeral head.

on both views postoperatively, at 12 months and at the final follow-up.

Statistical analysis. Means and standard deviations (SD) were calculated with Stat View (Abascus Concepts, Version 2, Berkeley, California) for the Macintosh computer. Differences between groups were tested using the chi-squared 
test and differences in parametric data by the unpaired, two-tailed Student's $t$-test. A p value $<0.05$ was considered significant.

\section{RESULTS}

There were no significant differences between conservatively and surgically-treated patients after one year or after more than three years (Tables II and III), nor was there any difference in function (Table III). Surgery improved the position of the fragments, which remained unchanged throughout the study, but also caused more complications (Table IV). None of the operated patients had a peroperative surgical complication. Two, with problems of alcohol abuse, developed deep infections which were successfully treated with antibiotics. One of these patients, however, developed AVN, had poor shoulder function after one year, and died from an unrelated cause one year later. The other patient with infection had a Constant score of 70 at the time of the final follow-up reflecting a good level of function. One patient had a pulmonary embolus but recovered completely. In one patient the K-wires penetrated the skin and had to be removed after three weeks; the fracture healed in an acceptable position and the functional result at the oneyear follow-up was good.

There were no significant differences in shoulder function between the groups either at the one year or at the final follow-up and there was little improvement after one year (Table II).

The mean Constant score in the surgery group was $60 \pm$ 19 points, and in the conservative group $65 \pm 15$ points.
There were no significant differences in shoulder function between the groups regarding pain, range of motion, power, or activities of daily living (Table III). Of the three patients with four-part fractures, two treated conservatively scored 70 and 73 points, but the third, treated surgically, scored 13 points. The fracture in the surgically-treated patient did not unite, and osteoarthritis followed. The pain subscale reflected mild pain in both groups. The mean value for power was 8 out of 25 points in both groups. Both groups scored a mean of 16 out of 20 points in activities of daily living reflecting restoration of good function of the injured shoulder.

Complications were found to occur mainly in the surgically-treated group (Table IV). One patient with a threepart fracture had AVN (after deep infection) and one with a four-part fracture had nonunion. The rest of the fractures in both groups healed uneventfully with no signs of AVN or osteoarthritis. At the final follow-up the fracture which was ununited after one year had not healed and osteoarthritis had developed. Three other patients, one surgically and two conservatively treated, developed osteoarthritis. No further cases of AVN were found in either group (Table IV). In all surgically-treated patients, the position of the greater tuberosities remained unchanged throughout the study, but in the conservatively-treated group only 12 of the 15 greater tuberosities were unchanged in position. Preoperatively, the dorsal angulation of the humeral head on the shaft in a lateral view did not differ between the two groups. Surgical reduction improved the dorsal angulation from $50^{\circ}$ (25 to 150) to $21^{\circ}$ (0 to 65) and did not change at the final followup (Fig. 2). The position of the humeral head in the

Table III. Functional assessment (mean \pm SD) at the final follow-up at 50 months for both groups

\begin{tabular}{lcc}
\hline & Surgery $(\mathbf{n}=\mathbf{1 4})$ & Conservative $(\mathbf{n}=\mathbf{1 5})$ \\
\hline Constant score $(\max 100)$ & $60 \pm 19$ & $65 \pm 15$ \\
Pain $(\max 15)$ & $10 \pm 5$ & $12 \pm 3$ \\
Range of motion $(\max 40)$ & $26 \pm 4$ & $29 \pm 3$ \\
Power $(\max 25)$ & $8 \pm 5$ & $8 \pm 5$ \\
$\begin{array}{l}\text { Activity of daily living } \\
(\max 20)\end{array}$ & $16 \pm 5$ & $16 \pm 4$ \\
\hline
\end{tabular}

Table IV. Complications in eight patients

\begin{tabular}{|c|c|c|c|c|c|c|c|c|c|}
\hline Case & Gender & $\begin{array}{l}\text { Age } \\
(\mathbf{y r})\end{array}$ & Operation & Infection & $\begin{array}{l}\text { K-wire } \\
\text { penetration }\end{array}$ & $\begin{array}{l}\text { Pulmonary } \\
\text { embolus }\end{array}$ & AVN & Nonunion & Osteoarthritis \\
\hline 1 & 69 & M & Yes & Yes & & & Yes & & \\
\hline 3 & 78 & $\mathrm{~F}$ & Yes & Yes & & & & & \\
\hline 4 & 63 & $\mathrm{~F}$ & Yes & & & Yes & & & \\
\hline 6 & 74 & $\mathrm{~F}$ & Yes & & & & & & Yes \\
\hline 7 & 81 & $\mathrm{~F}$ & No & & & & & & Yes \\
\hline 8 & 78 & $\mathrm{~F}$ & No & & & & & & Yes \\
\hline
\end{tabular}


conservatively-treated shoulders also remained unchanged throughout the study at $52^{\circ}$ (20 to 150$)$.

\section{DISCUSSION}

Because many elderly people have osteopenia, plates and screws provide poor fixation for fractures of the upper humerus, ${ }^{27}$ which is why we used a tension-band wiring technique in our study. At final follow-up only one patient had AVN after surgical treatment, indicating that the blood supply to the humeral head had not been critically impaired by open reduction in the others. Although a standard surgical technique had been used by an experienced surgeon, almost all the complications were in the operated group (Table IV). We do not believe that the exposure could have been performed with less disruption of the tissues, or with less internal fixation.

There were no complications in the conservative group, except for the radiological findings of osteoarthritis in two patients. A report of 12 patients with comminuted fractures of the proximal humerus treated by open reduction and internal fixation with one single cerclage wire showed no cases of AVN. ${ }^{21}$ A comparative series ${ }^{8}$ reported an incidence of AVN of $34 \%$ in patients operated on by plate fixation, but of only $10 \%$ when a tension band or simple lag screw was used. We also found relatively few complications in our surgical group; but there were significantly more than in the conservative group.

Both patients with a wound infection were alcohol abusers, a fact not known at the time of surgery. By our criteria they should not have entered the study and reinforce our view that alcohol abuse is a relative contraindication to surgery. The only case of nonunion and subsequent osteoarthritis occurred in the surgical group. The other operated patient who developed osteoarthritis scored 50 on the Constant score reflecting good age-matched final shoulder function.

In $1970 \mathrm{Neer}^{2}$ stated that three-part fractures could be successfully treated by open reduction and internal fixation. For four-part fractures he recommended replacement of the humeral head. Since then numerous articles on the treatment of these difficult fractures have been published $^{18,19,22,24,25,27,28}$ but none has matched the excellent results presented by Neer.

The variety of treatments and results indicates that no clear guidelines are available ${ }^{3,5}$ and one reason may be the difficulty in designing and interpreting a proper classification system. ${ }^{29,30}$ An example of this are the findings in our patients with three-part fractures and those of a retrospective study ${ }^{25}$ in which moderate pain and poor motion were common. As only three patients in our study had fourpart fractures, no conclusions can be drawn but two of these patients finally had an acceptable functional outcome.

The surgical procedure which we used was successful in terms of improving the fracture position, and the semi-rigid fixation with cerclage wires maintained the postoperative position of the fractured humeral head until healing was established. It has been stated that an important prerequisite for good functional outcome is non-displaced tuberosities, ${ }^{3}$ and that poor results follow displaced tuberosities. In our study the position of the greater tuberosities achieved at surgery was maintained in all 14 shoulders, perhaps explaining the relatively good results in the surgical group. Although we were able to improve and maintain the fracture position by operation, we could find no evidence to suggest that these patients had a better functional outcome than patients treated conservatively. Other studies have reported good results for the conservative treatment of three- and four-part fractures in elderly patients ${ }^{10,11,31}$ and the patients were very satisfied. From the answers to the questionnaire at the one-year and at final follow-up it seemed that improvement did not occur after one year.

We conclude that the outcome of surgical and conservative treatment of three-part fractures of the proximal humerus in elderly patients is similar, and more complications are found in the surgically-treated group. Regardless of the type of treatment optimal shoulder function is reached within one year and does not improve after that. In elderly patients conservative treatment should be considered for displaced three-part fractures of the humerus.

No benefits in any form have been received or will be received from a commercial party related directly or indirectly to the subject of this article.

\section{REFERENCES}

1. Horak J, Nilsson BE. Epidemiology of fracture of the upper end of the humerus. Clin Orthop 1975;112:250-3.

2. Neer CS II. Displaced proximal humeral fractures. Part II. Treatment of three-part and four-part displacement. J Bone Joint Surg [Am] 1970; 52-A:1090-103.

3. Mills HJ, Horne G. Fractures of the proximal humerus in adults. J Trauma 1985;25:801-5.

4. Jacob RP, Kristiansen T, Mayo K, Ganz R, Muller ME. Classification and aspects of treatment of fractures of the proximal humerus. In: Bateman JE, Welsh RP. Surgery of the shoulder. Philadelphia: BC Decker Inc, 1984:330-43.

5. Cofield RH. Comminuted fractures of the proximal humerus. Clin Orthop 1988;230:49-57.

6. Szyszkowitz R, Seggl W, Schleifer P, Cundy PJ. Proximal humeral fractures: management techniques and expected results. Clin Orthop 1993;292:13-25

7. Knight RA, Mayne JA. Comminuted fractures and fracture-dislocations involving the articular surface of the humeral head. J Bone Joint Surg [Am] 1957;39-A:1343-55.

8. Sturzenegger M, Fornaro E, Jakob RP. Results of surgical treatment of multifragmented fractures of the humeral head. Arch Orthop Trauma Surg 1982;100:249-59.

9. Einarsson F. Fractures of the upper end of the humerus: discussion based on the follow-up of 302 cases. Acta Orthop Scand Suppl 1958;32:131-42.

10. Clifford PC. Fractures of the neck of humerus: a review of the late results. Injury 1981;12:91-5.

11. Zyto K, Kronberg M, Broström L-Å. Shoulder function after displaced fractures of the proximal humerus. J Shoulder Elbow Surg 1995;4:331-6.

12. Kraulis J, Hunter G. The results of prosthetic replacement in fracture dislocation of the upper end of the humerus. Injury 1977;8:129-31.

13. Paavolainen P, Björkenheim J-M, Slätis P, Pauku P. Operative treatment of severe proximal humeral fractures. Acta Orthop Scand 1983;54:374-9. 
14. Tanner MW, Cofield RH. Prosthetic arthroplasty for fractures and fracture-dislocations of the proximal humerus. Clin Orthop 1983; 179:116-28.

15. Stableforth PG. Four-part fractures of the neck of the humerus. J Bone Joint Surg [Br] 1984;66-B:104-8.

16. Willems WJ, Lim TEA. Neer arthroplasty for humeral fracture. Acta Orthop Scand 1985;56:394-5.

17. McIlveen SJ, Neer C. Recent results and technique of prosthetic replacement for four part proximal humeral fractures. AAOS 53rd Annual Meeting final program 1986;107.

18. Sehr JR, Szabo RM. Semitubular blade plate for fixation in the proximal humerus. J Orthop Trauma 1988;2:327-32.

19. Moda SK, Chada NS, Sangwan SS, et al. Open reduction and fixation of proximal humeral fractures and fracture dislocations. J Bone Joint Surg [Br] 1990;72-B:1050-2.

20. Esser RD. Open reduction and internal fixation of three and four-part fractures of the proximal humerus. Clin Orthop 1994;299:244-51.

21. Lee CK, Hansen HR. Post-traumatic avascular necrosis of the humeral head in displaced proximal humeral fractures. J Trauma 1981;21:788-91.

22. Kristiansen B. Treatment of displaced fractures of the proximal humerus: transcutaneous reduction and Hoffmann's external fixation. Injury 1989;20:195-9.
23. Hawkins RJ, Bell RH, Gurr K. The three-part fracture of the proximal part of the humerus: operative treatment. J Bone Joint Surg [Am] 1986;68-A:1410-4.

24. Cornell CN, Levine D, Pagnani MJ. Internal fixation of proximal humerus fractures using the screw-tension band technique. J Orthop 1994;8:23-7.

25. Jones AR, Brashear HR, Dameron TB. Surgical neck fracture of the humerus with severe displacement: factors related to union. Orthop Trans 1987;11(3):457.

26. Constant CR, Murley AHG. A clinical method of functional assessment of the shoulder. Clin Orthop 1987;214:160-4.

27. Cofield RH. Total shoulder arthroplasty with the Neer prosthesis. J Bone Joint Surg [Am] 1984;66-A:899-906.

28. Jacob R, Miniac A, Anson PS, et al. Four-part valgus impacted fractures of the proximal humerus. J Bone Joint Surg [Br] 1991; 73-B:295-8

29. Sidor ML, Zuckerman JD, Lyon T, et al. The Neer classification system for proximal humeral fractures: an assessment of interobserver reliability and intraobserver reproducibility. J Bone Joint Surg [Am] 1993;75-A: $1745-50$

30. Siebenrock KA, Gerber C. The reproducibility of classification of fractures of the proximal end of the humerus. J Bone Joint Surg [Am] 1993;75-A:1751-5.

31. Leyshon RL. Closed treatment of fractures of the proximal humerus. Acta Orthop Scand 1984;55:48-51. 